\title{
A infância e a coragem de ser: \\ o que não está no diálogo entre \\ Carl Rogers e Paul Tillich
}

\author{
Elton Vinicius Sadao Tada ${ }^{1}$ \\ Verônica Regina Müller ${ }^{2}$
}

\begin{abstract}
RESUMO
O presente trabalho busca apresentar um conceito de infância a partir do diálogo entre Paul Tillich e Carl Rogers. O conceito de infância será relacionado com o conceito tillichiano de coragem de ser, de modo a discutir a possibilidade da criança como uma inspiração para a coragem de ser de qualquer sujeito.

Palavras-chave: Infância; Coragem de Ser; Criança; Paul Tillich; Carl Rogers

\section{CHILDHOOD AND COURAGE TO BE IN THE DIALOGUE BE- TWEEN CARL ROGERS AND PAUL TILLICH}

\begin{abstract}
The present paper aims to show a concept of childhood parting from the dialogue between Paul Tillich and Carl Rogers. The concept of childhood will be related with Tillich's concept of courage to be, discussing, this way, the possibility of children as inspiration of courage to be.

Key-words: Childhood; Courage to be; child; Paul Tillich; Carl Rogers.
\end{abstract}

\section{Introdução}

Paul Tillich (1886-1965), ao longo da sua carreira desenvolveu um histórico de encontros com diversas personalidades e pensadores ao re-

1 Teólogo. Mestre e Doutor em Ciências da Religião pela Universidade Metodista de São Paulo. Doutorando em Educação pela Universidade Estadual de Maringá.

2 Licenciatura em Educação Física pela Universidade Federal de Santa Maria. Mestrado em Educação pela PUC-RS. Doutorado e pós-doutorado em História da educação Social Contemporânea pela Universidad de Barcelona 
dor do mundo ${ }^{3}$. Um desses encontros foi com Carl Rogers (1902-1987), em março de 1965, na Califórnia. Esse diálogo foi gravado e contamos com o mesmo disponível, em áudio e vídeo para consulta na internet ${ }^{4}$. $\mathrm{Na}$ ocasião, Tillich era professor da Universidade de Chicago, depois de ter passado pelo Union Theological Seminary de Nova York, pela Columbia University e por Harvard. Tillich tinha setenta e oito anos, e esta acabou sendo sua última grande aparição pública. Tillich viria a falecer em outubro do mesmo ano. O narrador que faz as apresentações do vídeo diz que naquele momento Tillich já teria recebido 13 títulos de doutorado honoris causa de diversas universidades.

Carl Rogers, por sua vez, estava com 63 anos e já era um pensador bastante conhecido, sendo inclusive presidente da Associação Norte-americana de Psicoterapia.

O diálogo entre ambos parece ser uma espécie de entrevista na qual Rogers pergunta a Tillich sua opinião sobre alguns assuntos, ao mesmo tempo em que apresenta seu ponto de vista e que expõe alguns conceitos clássicos do pensamento tillichiano, especialmente, o conceito de demoníaco.

No início, ambos falam sobre a autoafirmação do indivíduo e a conversa se desenvolve de modo que chegam em determinado momento a falar sobre a infância. Esse é o ponto que nos interessa com mais especificidade, pois Tillich não foi um pensador que se dedicou muito ao estudo da infância ou que tenha tematizado a criança como uma de suas questões principais. Mesmo assim, ao discutir a natureza do ser humano e os âmbitos simbólicos da linguagem na expressão dessa natureza, Tillich aponta para elementos que podem ser úteis para uma reflexão mais ampla sobre as infâncias e as crianças.

A temática da infância, que foi levantada no diálogo, por Rogers, acaba sendo considerada por Tillich como algo "muito importante". Nosso trabalho consiste em compreender a discussão sobre infância

3 Um texto que mostra as principais conexões de Tillich é o artigo de Carlos Eduardo Calvani "Aspectos biográficos, referenciais teóricos e desafios teológicos, publicado na revista Estudos de Religião número 10, de 1995. No texto Calvani aponta a relação de Tillich com Theodor Adorno, Max Horkheimer, Erich Fromm, Martin Heidegger, entre outros.

4 disponível em: https://www.youtube.com/watch?v=8gHSKdX66tY\&t=192s Acesso em $15 / 05 / 2020$. 
entre Rogers e Tillich e, em seguida, discutir aspectos da infância a partir do conceito tillichiano de coragem de ser.

\section{A temática da infância entre Rogers e Tillich}

Paul Tillich, questionado por Rogers, apresenta de modo sumário seu conceito de demoníaco. Para situarmos como a questão da infância se insere na discussão, trazemos primeiramente a apresentação que Tillich faz de seu conceito de demoníaco ${ }^{5}$ :

O único termo adequado que encontrei foi o uso pelo Novo Testamento do termo "demônico", que se encontra nas histórias acerca de Jesus: similar ao estar possesso. Isso significa uma força, debaixo de uma força, que é mais forte do que a boa vontade do indivíduo. Por esse motivo usei esse termo. Quero deixar bem claro que não me refiro a um sentido mitológico - como pequenos demônios ou o próprio Satanás correndo pelo mundo - mas me refiro a estruturas que são ambíguas, ambas, até certo ponto, criativas, mas, em sentido último, destrutivas. Essa é a razão por ter introduzido esse termo. Assim, em vez de falar apenas de uma humanidade alienada, e não usando a terminologia antiga casualmente, tive de achar um termo que abrangesse o poder interpessoal que se apodera dos homens e da sociedade (ROGERS;TILLICH, 2008, p.123).

Tillich faz questão de ressaltar que não fala de demoníaco no sentido mitológico, mas utiliza o termo como forma de expressar uma força que toma o ser humano em seus atos, um poder interpessoal, que atua acima da força do ser humano comum. Essa força que Tillich pretende explicar chamando-a de demoníaca é a força potencial que surge da própria alienação da humanidade. Esse termo será central para a discussão que aqui se faz sobre alienação.

Após Tillich concluir sua explicação sobre a origem do conceito de demoníaco, Rogers comenta que em sua prática, testemunha atos que o fazem compreender tal conceito. Na sequência ele indaga a Tillich:

Gostaria de falar um pouco acerca da forma como vejo essa questão da alienação e do distanciamento. Parece-me que o infante não é alienado

5 O termo inglês demonic, utilizado por Tillich conta com uma dupla possibilidade de tradução ao português: demônico ou demoníaco. O tradutor do diálogo entre Carl Rogers e Paul Tillich escolhe o termo português demônico enquanto nós escolhemos o termo demoníaco. 
por si só. Parece-me que a criança é um organismo completo e integrado, gradualmente individual, e que a alienação que ocorre é algo que ela aprende - que para preservar o amor dos outros, dos pais geralmente, ela toma para si algo que experimentou por si próprio, o julgamento de seus pais: semelhante ao pequeno garoto que foi repreendido por ter puxado o cabelo da irmã e sai por aí dizendo: "menino mau, menino mau". Enquanto isso, ele volta a puxar o cabelo dela novamente. Em outras palavras, ele fez uma introjeção da noção de que ele é mau, quando na verdade está gostando da experiência, e é essa alienação entre o que está experimentando e os conceitos aos quais está ligado com o que ele está experimentando que, me parece, constituem a alienação básica. Não sei se você quer comentar a esse respeito [...] (ROGERS;TILLICH, 2008, p.123-124).

Basicamente, Rogers está retomando a problemática da alienação e explicando seu surgimento no desenvolvimento do ser humano enquanto indivíduo. Da fala de Rogers podemos destacar três pontos: 1 - "o infante não é alienado por si só”; 2 - "a criança é um organismo completo e integrado"; e que 3 - "a alienação é algo que a criança aprende". Ora, a hipótese que nos surge é que uma vez que o conceito tillichiano de demoníaco está relacionado com a alienação da humanidade e a criança está fora dessa alienação, a criança seria, por excelência o não-demoníaco, ou até mesmo o anti-demoníaco. À medida em que a cultura vai sendo inserida no ser humano, ele vai se afastando de sua natureza não-demoníaca e se alienando em prol de uma vida com potências demoníacas. A completude e integração das crianças se devem justamente à ausência da estrutura neurótico-psicótica que marca a vida adulta, e que vai se desenvolvendo ao longo das experiências da vida.

Na sequência do diálogo, Tillich aceita comentar sobre a temática proposta por Rogers, no que diz:

Sim, eu gostaria. A criança é uma questão muito importante. Chamo isso em termos filosóficos, ou, melhor, psicológicos, o estado mitológico de Adão e Eva antes da Queda: a inocência sonhadora. Ainda não alcançou a realidade; ainda está sonhando. É claro, isso também é um símbolo, mas é um símbolo que está mais próximo da nossa linguagem psicológica do que a Queda de Adão e Eva, mas significa a mesma coisa, e significa que Adão, a saber, o homem - o hebraico "Adão" significa homens - esses homens, cada homem, está no processo de transição da inocência sonhadora para a auto-atualização consciente, e nesse processo, 
a alienação também toma parte, bem como a realização; esse é o motivo do meu conceito de ambigüidade (ROGERS; TILLICH, 2008, p.124).

Tillich traça uma correlação entre o estado pré-queda (a sucumbência ao pecado) da humanidade com a condição da infância. Ele afirma, inclusive, que a explicação pela via do desenvolvimento psicológico da criança está mais próxima da realidade do que o conceito mitológico da queda, apresentado na narrativa de Adão e Eva. O termo que Tillich usa para designar a condição da criança, correlacionando com o estado pré-queda é a inocência sonhadora. O termo inocência sonhadora, se utilizado fora de contexto, pode parecer uma abordagem romântica da infância. Entretanto, Tillich faz questão de explicar o caráter simbólico do termo. A inocência sonhadora nos aponta para a condição na qual o ser humano ainda não experimentou a alienação de sua existência, estando ainda em sua completude e integridade. Esse ser completo em si mesmo é uma experiência de auto-realização, o que seria em termos existenciais a mais justa forma de se viver. E a criança é a concretude desse ser. Exatamente esse ponto será adiante relacionado com o conceito tillichiano de coragem de ser, pois, apesar de Tillich não fazer tal correlação, nos parece que a criança é o máximo da experiência individual de coragem de ser como si mesmo. Ser criança, seria, portanto, a forma mais auto-realizada, mais completa de existência do ser humano. Nesse sentido, se comprova nossa hipótese acima levantada de que a criança é uma espécie de não-demoníaco.

Continuando o diálogo, Tillich aponta para Rogers:

Concordo com você que há também naquilo que os pais costumavam chamar de "menino mau" ou "menina má", um ato de auto-realização necessário, mas também há algo de anti-social nisso, porque isso machuca sua irmã e, por isso, precisa ser reprimido, e que digamos "menino mau", ou o impedimos de qualquer outra forma, isso é igualmente necessário, e essas experiências significam para mim o lento processo de transição da inocência sonhadora para a realização própria de um lado, e auto-alienação do outro, e, esses dois atos são ambiguamente mesclados. Essa seria a minha interpretação da situação das crianças (ROGERS; TILLICH, 2008, p.124). 
Tillich explica nesse momento as consequências da transição da infância para a condição de adulto. Essa transição gera um dos principais conceitos tillichianos, a ideia de ambiguidade da vida. Segundo Tillich, quando o pai e a mãe inserem a cultura na criança a partir de sua vocação "menino mau", há também um ato de auto-realização no menino. A ética e a moralidade fazem parte da existência de modo que a ação dos pais frente a um filho que incomoda a irmã puxando seu cabelo, é uma atitude correta. Entretanto, lembremos que no exemplo dado por Rogers a questão não é simplesmente a admoestação materno-paterna, mas introjeção de um princípio moral/cultural no sistema da criança que até então estava em seu sonho inocente. Essa introjeção faz com que o menino diga a si mesmo "menino mau", apesar de continuar puxando o cabelo de sua irmã, pois a experiência lhe é positiva. No exemplo de Rogers, nota-se como há uma dupla presença na atitude da criança, a experiência que lhe parece positiva de puxar o cabelo da irmã e a negação de seu próprio ato através da auto-vocação de seu julgamento moral "menino mau".

Tillich aceita, portanto, que há no desenvolvimento humano esse momento da queda, da transição da inocência sonhadora para uma consciência adulta. É importante notar que, para Tillich, abre-se um duplo caminho, o caminho da auto-realização de um lado e o caminho da alienação do outro. Apesar do adulto estar distante de seu estado completo e íntegro, a infância, ele também não se apresenta como completamente alienado. Ele se aliena parcialmente e se auto-realiza parcialmente em momentos específicos da história. Esse princípio gera na condição do adulto a ambiguidade, que é uma sobreposição lógica a partir da materialidade da existência. Ou seja, pela via lógica entende-se que o indivíduo em domínio de seu juízo e almejando sua completude e integridade busca sua auto-realização. Entretanto, segundo o autor, pelo mecanismo da estrutura neurótico-psicótica o adulto se aliena de si mesmo, se fragmenta e destrói ao invés de se auto-realizar. Essa sobreposição dos dois caminhos gera a ambiguidade da vida, que é própria da existência do ser humano em sua condição adulta.

Como não há um momento específico em que a criança deixa de ser criança totalmente e passa a ser adulto totalmente, o que existe de fato, para Tillich, é uma transição contínua e longa na qual a inocência 
sonhadora vai dando espaço para as neuroses da vida adulta. Portanto, a partir do momento em que o indivíduo começa a receber/viver a cultura e a introjetá-la não em termos de auto-realização, mas de alienação, a condição de adulto começa a permear a existência daquele indivíduo e o mesmo vai se tornando ambíguo em uma escala com infinitas possibilidades, até que a ambiguidade lhe seja presença majoritária, abandonando assim, quase totalmente sua natureza de inocência sonhadora. O diálogo continua com a participação de Rogers:

Bem, concordo com boa parte do que você disse. Gostaria de dizer um pouco a respeito do tipo de relacionamento em que, acredito, a alienação humana pode ser curada, de acordo com a minha própria experiência. Por exemplo, quando conversamos a respeito de - quando um de nós fala a respeito da coragem de ser ou da tendência de se tornar si mesmo, sinto que, talvez, isso só possa ser completamente alcançado em um relacionamento (ROGERS; TILLICH, 2008, P.125).

Rogers concorda com o exposto por Tillich sobre a ambiguidade da vida, a correlação entre o mito pré-queda e o que estamos chamando aqui de estado de infância, e a transição da infância para a condição adulta a partir da introjeção das neuroses. Em seguida, Rogers fala sobre o processo terapêutico como relacionamento de aceitação, e pergunta a Tillich sobre sua ideia de relacionamentos interpessoais, ao que ele responde:

Acredito que você está absolutamente certo ao dizer que a experiência mútua de perdão, ou melhor, de aceitação do inaceitável, é uma precondição necessária para a auto-afirmação. E você não consegue perdoar a si mesmo, você não pode aceitar a si mesmo. Se olhar no espelho espiritual, então você está muito mais propenso a odiar a si mesmo e a estar aborrecido consigo mesmo. Assim, acredito que todas as formas de confissão nas igrejas, e as confissões entre amigos e pessoas casadas - e igualmente a confissão sacro-analítica dos níveis mais profundos de uma pessoa que se tornam acessíveis ao analista - que sem essas coisas, não há possibilidade de experimentar algo que pertence em última instância a uma outra dimensão: a dimensão do fim último, se me permite chamá-la preliminarmente assim. Mas eu diria, com você, que somente a aceitação correta é o ambiente pelo qual o homem necessariamente tem de passar - do homem para o homem - antes que a dimensão do fim último seja possível (ROGERS; TILLICH, 2008, P.125). 
Tillich não fala mais de infância nesse momento, mas a correlação feita inicialmente ainda é válida, de modo que a alienação, que gera a possibilidade do demoníaco, só pode ser superada pelo perdão, que Tillich prefere chamar de aceitação do inaceitável. É importante essa mudança terminológica, pois a partir dela podemos entender que a possibilidade de auto-afirmação do indivíduo adulto em sua existência depende justamente da compreensão da ambiguidade, da aceitação daquilo que é absolutamente inaceitável. A aceitação, como tal, seria a ponte do indivíduo adulto, fragmentado, para uma experiência de superação da alienação, a ambiguidade, e, consequentemente, do demoníaco, a força destrutiva. Em termos correlatos, podemos entender que a aceitação do inaceitável é o que nos permite tocar, a partir da condição de adultos, na condição de inocência sonhadora da infância.

Contudo, assim como não há na narrativa mitológica judaico-cristã um retorno ao paraíso pré-queda - ou seja, ao estado de inocência de Adão e Eva -, não há no desenvolvimento do indivíduo o retorno à inocência sonhadora. Ou seja, não é possível voltarmos a ser crianças. Há, no entanto, na narrativa mitológica soteriológica a possibilidade de uma justificação para a entrada em um novo paraíso, a partir de uma natureza reformada, aquilo que é chamado de céu na mitologia cristã e de novo ser no pensamento tillichiano. Qual seria, portanto o correlato da mitologia para o desenvolvimento do indivíduo em sua existência? Em termos tillichianos seria o novo ser. Para a construção dessa leitura correlacional que Tillich não fez, mas que vemos agora a possibilidade de fazer, na continuidade, analisamos o conceito de coragem de ser relacionado à infância.

\section{Infância e coragem de ser}

A coragem de ser é um dos últimos conceitos desenvolvidos por Tillich. Também acabou se tornando um dos principais conceitos tillichianos, marcando seu posicionamento como pensador em sua maturidade. Lá, em 1952, Tillich escrevia na edição original que a coragem precisa ser compreendida ontologicamente para que possa ser compreendida eticamente:

Poucos conceitos têm tanta utilidade para a análise da situação humana.

Coragem é uma realidade ética, mas se enraíza em toda extensão da 
existência humana e basicamente na estrutura do próprio ser. Deve ser considerada ontologicamente a fim de ser entendida eticamente (TILLICH, 1976, p.1)

A compreensão da situação humana é um dos grandes esforços de Tillich, tanto quanto das ciências humanas, em geral. Nesse sentido, direcionamos a discussão sobre a coragem de ser para a infância, pois a compreensão da infância é parte ativa da compreensão da situação humana.

Como vimos anteriormente, no diálogo entre Rogers e Tillich existe uma apresentação simbólica por parte de Tillich para a compreensão da ideia de infância, a ideia de inocência sonhadora. Tal condição coloca o ser humano em estado de completude e integridade, condição tal que é perdida de acordo com a entrada da cultura na existência do indivíduo. Assim, a sã completude infantil vai sendo substituída pela estrutura de neurose/psicose que gera a ambiguidade, marca da vida do ser humano adulto.

A coragem entra nessa discussão justamente porque a coragem é o elemento fundamental de auto-afirmação do indivíduo: Coragem como a auto-afirmação do ser de alguém é um conceito ontológico. A coragem do ser é o ato ético no qual o homem afirma seu próprio ser a despeito daqueles elementos de sua existência que entram em conflito com sua auto-afirmação essencial (TILLICH, 1976, p.3)

Esse princípio é válido tanto para uma auto-afirmação individual quanto coletiva, como parte de uma estrutura maior. O ponto principal a ser compreendido aqui é que a coragem de ser se manifesta "in spite of", apesar de algumas condições. A coragem de ser é sempre uma coragem de vida apesar de elementos negativos que conflitam e ameaçam a existência. Essa constância se dá por uma condição fundamental para a vida adulta que é a ambiguidade. Os elementos positivos e negativos coexistem na vida de qualquer indivíduo.

Tillich recorre a Nietzsche para explicar a ambiguidade da coragem de ser:

A vida tem aspectos vários, é ambígua. Nietzche descreveu sua ambigüidade de forma mais típica no último fragmento da coleção de fragmentos denominada Vontade de Potência. Coragem é a potência da vida em se afirmar a despeito desta ambigüidade, enquanto que a negação da vida, 
devido sua negatividade, é uma expressão de covardia (TILLICH, 1976, P.21)

Nesse sentido, Tillich explica que na opinião de Nietzsche a negatividade seria uma expressão de covardia, o que explica a proposta nietzscheana de um ser humano com padrões superiores aos padrões humanos, um super-homem. O próprio Tillich não parece propor uma valoração moral dos elementos de negatividade da existência como o faz Nietzsche. Tillich propõe a aceitação da condição de ambiguidade como caminho para a coragem da transcendência.

No processo de construção do conceito de coragem de ser, Tillich apresenta com cuidado o conceito de ansiedade, que perpassa toda a ideia de coragem de ser, uma vez que não é eliminada pela coragem, mas integrada à ambiguidade da existência:

Mêdo e ansiedade são distintos mas não separados. São imanentes um dentro do outro: o acicate do medo é a ansiedade, e a ansiedade se esforça na direção do mêdo. Mêdo é estar assustado com algo, uma dor, a rejeição de uma pessoa ou um grupo, a perda de alguma coisa ou alguém, o momento de morrer. Mas na antecipação da ameaça que se origina destas coisas, o que está assustando não é a negatividade em si que eles trarão para o sujeito, porém a ansiedade sôbre as implicações possíveis desta ansiedade (TILLICH, 1976, p.29)

Enquanto o medo, que é direcionado a um objeto específico, gera um sentimento parcial de ameaça, a ansiedade, que é a antecipação de uma ameaça, pode gerar a negatividade da estrutura ambígua da existência. Um exemplo amplo, porém elucidativo sobre a questão, é que o indivíduo pode sentir medo da dor que vai sentir no momento de sua morte, mas sente ansiedade pela ameaça de não ser ${ }^{6}$, ameaça tal que pode se tornar patológica e impedir que essa pessoa consiga seguir adiante, haja vista a incerteza existencial que a acompanha atrás de cada esquina.

A ansiedade tillichiana parece ser a prova material da existência, assim como a angústia seria o exame clínico e laboratorial que com-

${ }^{6}$ O não ser, para Tillich, representa ameaça constante ao ser, seja em termos parciais ou absolutos, como no caso da morte. 
prova a existência em Kierkegaard ${ }^{7}$. A ansiedade é companheira da ambiguidade da existência e a estrutura psíquica de neurose/psicose consegue explicar os mecanismos de entrada e manutenção da ansiedade na vida do indivíduo. Entretanto, como estamos fazendo uma leitura de extensão do pensamento tillichiano, podemos nos questionar se a ansiedade atinge a inocência sonhadora que condiciona a infância.

Vale lembrar que o próprio Tillich não fez uma divisão sistemática da condição humana adulta com a condição infantil, mas deixou sinais da possibilidade de explicação da situação humana com tal distinção. Assim, a condição da infância, sua completude e integridade, não abre espaço para a ambiguidade da estrutura da existência, assim como não precisa se expressar em termos de ansiedade. A situação do ser humano na concepção da infância é uma existência livre de ansiedade, ainda que o medo possa ser possível.

A criança, em termos ontológicos, não sofre a ameaça do não-ser como um ser humano adulto. É bom lembrar que a inocência sonhadora da infância tillichiana é válida como narrativa simbólica, útil para a reflexão ontológica, mas limitada em suas consequências éticas pois na prática, a criança ao absorver a língua, a alimentação e os des/afetos parentais já passa, gradualmente a experimentar a ambiguidade e a ansiedade da existência.

Dada tal situação, o que seria, para um sujeito de qualquer idade, a coragem de ser criança? A coragem de ser criança é a auto-afirmação do indivíduo humano em situação de infância. A infância, como discutido ao longo do texto, é uma condição de inocência sonhadora, que conta com a ausência das ambiguidades da vida, não experimenta ansiedade e nem alienação, mas é completa em si mesma. Portanto, cabe-nos inferir que a infância é uma condição semelhante à condição do adulto que elimina a alienação e a ansiedade pela experiência da auto-afirmação, ou seja, um adulto completamente sadio, o que Tillich chamaria em termos metafóricos religiosos de novo ser. Assim, a infância seria o

\footnotetext{
7 A angústia é um termo caro para os pensadores da existência, em geral. Todavia, Soren Kierkegaard foi quem estabeleceu esse termo como algo inerente ao ser humano: "O que existe então? Nada. Que efeito produz, porém, este nada? Este nada dá nascimento à angústia. Aí está o mistério profundo da vida; é, ao mesmo tempo, angústia" (KIERKEGAARD, 1968, p. 45). Para Kierkegaard viver é sinônimo de angustiar-se, de modo que a angústia pode ser um sinal da própria existência.
} 
modelo existencial que o adulto deveria olhar na tentativa de se tornar sadio, na busca da coragem de ser. A infância seria a própria coragem de ser sem a potência negativa da alienação, condição para qual o adulto não pode regressar, pois já está fragmentado na estrutura de neurose/ psicose. A condição para o ser humano adulto voltar ao estágio máximo de coragem de ser, a infância, é que abandone sua alienação e aceite sua condição, que exista apesar da presença ameaçadora do não-ser, é tornar-se um novo ser.

Essa é a definição em termos ontológicos, mas quais seriam as consequências éticas dessa visão? A completude e integridade da inocência sonhadora da infância são reais antídotos para a alienação do ser humano que gera a negativa força da ação demoníaca. Portanto, como anti-demoníaca a infância deve ser tratada em seu papel profético e poético de resistência contra as forças negativas da existência.

\section{Considerações finais}

O diálogo entre Carl Rogers e Paul Tillich foi o impulsionador das elucubrações realizadas neste texto. Na conversa, os dois tangenciam quase que sutilmente a referência à criança, mas o suficiente para suscitar indagações sobre a infância sob o prisma filosófico. A partir daí decidimos dissertar sobre o que pensamos escutando-os, e não exatamente, sobre o que consta em seu diálogo.

No diálogo, Rogers e Tillich conversam livremente sobre algumas das teorias de Tillich com questionamentos e aproximações feitas por Rogers. O contexto em que surge o assunto da criança é quando Rogers pede para que Tillich explique seu conceito de demoníaco. Ao falar sobre a natureza humana para explicar o conceito de demoníaco, Tillich traz uma breve definição sobre a infância, da qual extraímos nossa leitura e para onde encaminhamos a reflexão sobre a coragem.

A coragem é um termo que, em sua origem traz uma simbologia muito forte. Coraticum, do latim cor + aticum é a ação do coração, na medida em que coração representa o ponto central da vivacidade e alma humana (CESCA, 2016). Nesse sentido, a coragem é um ato a ser recuperado na integralidade do ser humano, contra as forças alienantes da vida, que desintegram e separam o ser humano de seu próprio ser. Portanto, a coragem é fundamental para se viver em um mundo de 
divisão e afastamento da integralidade do ser humano. Como consequência de nossas considerações, argumentamos conclusivamente que a criança é o modelo para o qual essa coragem deve apontar, pois é no estado de ser criança, no "Estado de Infância" (Colavitto, 2019) que se pode experimentar o máximo da coragem de ser.

De acordo com nossa leitura sobre a ideia tillichiana de infância, a criança é corrompida pela cultura, de modo que as ideias e os costumes vão tomando o lugar da liberdade natural do ser humano no desenvolvimento do indivíduo. O mundo adulto vai dominando a criança a partir da entrada e introjeção da cultura no indivíduo. Entretanto, para nós isso não significa que devamos abominar ou evitar a cultura. A cultura é, de um modo ou de outro, uma consequência esperada do desenvolvimento em sociedade. O que se deve fazer é refinar os modos de cultura que são ensinados e introjetados nas crianças em sua transformação para o mundo adulto, em função da ética que consideramos adequada. No nosso caso, a da busca incessante da justiça social, da liberdade, da solidariedade, do cuidado com os seres vivos e com todo o planeta.

A cultura portanto, fonte de influências más, pode ser a fonte de boas influências. Se construirmos uma cultura de edificação da humanidade do ser humano, o indivíduo não se afastará tanto de seu ser 'íntegro conforme for entrando no mundo adulto. Ao contrário, terá mais proximidade da infância ao longo de toda sua vida, vivendo a partir de sua coragem de ser.

A forma de ser do adulto em relação com a criança nas políticas e em outros setores, tem sido historicamente inadequada para os princípios éticos aqui ressaltados. A criança tem sido abandonada pelas mais diversas instituições, tem tido sua força e liberdade suprimidas pela conveniência e pela tradição opressora (TADA; MULLER, 2019). A escola, instituição social da política pública que, no ocidente, mais regula e domina a vida das crianças, não está configurada de modo a criar uma cultura de humanidade. Longe disso, a escola costuma agir com uma lógica de domesticação, em semelhança à lógica prisional e manicomial. O formato de escola que conhecemos hoje não é suficiente para o desenvolvimento saudável da criança.

Entre tantas políticas específicas que devem priorizar os sujeitos crianças para suas determinações, e se otimizarem para a concreção da 
formação humana, a política da educação escolar precisa ser complementada pela política da educação social (SOUZA, 2014), uma educação que seja mais ampla do que um local e um tempo pré-determinado. Uma educação que leve em conta a natureza básica e as condições sociais que são trazidas na bagagem da própria criança, as necessidades e interesses da infância, e que respeite a criança como sujeito político (RODRIGUES, 2014), promotor de cultura, ator de transformação de sua realidade e da sociedade em geral.

A educação social já é uma modalidade de educação estabelecida em alguns países do mundo, mas ainda carece de atenção em sociedades como a brasileira, que tanto se beneficiariam de uma forma supra escolar de educação para a infância.

Como bem sabemos, o indivíduo adulto não pode retomar sua infância, não pode deixar de ser aquilo que é, com suas naturais condicionantes e limitações. No entanto, o adulto pode buscar na infância (convivendo com crianças e acessando seus conteúdos/sentimentos/ sensações/memórias ) elementos que o instruam rumo à sua coragem de ser, seja na coragem de ser como parte, na coragem de ser como si próprio, ou na coragem de aceitar a aceitação. Mas, para que isso seja alcançado em qualquer momento da vida, há de se mudar passo a passo o trato com as crianças, a concepção de infância e a distância entre o mundo adulto e o mundo infantil.

A coragem de ser, tendo como base a infância deve levar o ser humano a experimentar o ser de modos que são hoje simplesmente ignorados. A infância é basicamente o elemento neutralizador das alienações que nutrem atitudes demoníacas dos seres humanos. A destruição demoníaca, a injustiça, perversidade e covardia podem ser objetivamente combatidas a partir do corajoso modelo de ser e de coragem que vem da infância. Assim, ao invés de violência e morte, de opressão e repressão, de prisão e cerceamento, as relações humanas podem passar a ser suleadas pela brincadeira, pela fantasia, pelo riso, pelo prazer, pelo erro e acerto, pela curiosidade, pelo desafio, pelo invento, pela alegria de estar em grupo e podem mesmo chegar ao grau de poesia. Não há potencial demoníaco onde a relação entre entes seja poesia. Ser como criança é ser poeticamente político, enfrentando qualquer potencial demoníaco com a coragem do próprio ser. 


\section{Referências}

CALVANI, C.E. Paul Tillich - Aspectos biográficos, referenciais teóricos e desafios teológicos. In: Revista estudos de Religião, ano X, n. 10, pp. 11-35. São Bernardo do Campo: UMESP, julho de 1995.

CESCA, V. Dicionário genealógico latino-português. Porto Alegre: EdiPucRS, 2016.

COLAVITTO, M. A. Estado de infância: a poiesis na arte da palhaçaria. Tese de doutorado. Maringá: ppe/uem, 2019.

KIERKEGAARD, Soren A. O conceito de angústia. São Paulo: Hemus, 1968. RODRIGUES, Patricia Cruzelino. Participação política de meninos e meninas: expedições de experiências e reflexões em curso. Dissertação de mestrado. Maringá ppe/uem, 2014.

ROGERS, C.; TILLICH, P. Diálogo. Tradução: Marcos Ricardo Janzen Revisão Técnica: Gustavo Vieira da Silva e Adriano Holanda. Revista da Abordagem Gestáltica - XIV(1): 121-127, jan-jun, 2008.

SOUZA, C. R. T.; PAIVA, J.; NATALI, P. M.; BAULI, R. A.; MÜLLER, V. R.. A atuação profissional e formação do educador social no Brasil. In: Revista Interfaces Científicas - Educação • Aracaju • V.3 • N.1 • p. 77 - 88 - Out. 2014.

TADA, E. V. S; MÜLLER, V. R.Educação para a infância na América Latina: uma perspectiva a partir da teologia da cultura. In: Revista eletrônica Correlatio v. 18 , n. 2 (2019)

TILLICH, Paul. A coragem de ser. São Paulo: Terra e paz, 2000.

TILLICH, P. The courage to be. 2 ed. New haven: Yale, 2000. 